\title{
The Epithelial Papillae of the Mouse Buccal Mucosa
}

\author{
By \\ Norio OZEKI, IkUo YOSHIOKA and Hiroshi MUTO \\ Department of Anatomy, Aichi Medical University, \\ Nagakute, Aichi 480-11, Japan \\ - Received for Publication, March 21, 1980-
}

Key words: Scanning electron microscopy, Buccal mucosa, Epithelial papilla, Mouse.

Summary. The mouse buccal mucosa was observed with a scanning electron microscope and a light microscope.

1. Many epithelial papillae, termed buccal papillae by Yoshioka and Muto, projecting from the oral surface were observed on the buccal mucosa. The buccal papillae contained connective tissue papillae but no secondary papillae. Their form was classified into the following types; filiform papilla type or wart type, beak type, flat oval type, and transitional types between these.

2. Buccal papillae were abundant in the posterior and middle parts of the buccal mucosa, but were not seen in the anterior part. The border region (Schumacher) could not be distinguished on the basis of the surface structure of the mouse buccal mucosa. The buccal papillae showed no close relationship to the border region in their distribution.

3. In the closed state of the mouth, the buccal mucosa exhibited rising of the surface, greater thickness of the epithelium and higher connective tissue papillae, but these findings were not remarkable in the opening state. It is therefore questionable histologically whether to distinguish the border region from the buccal mucosa.

\section{Introduction}

The buccal mucosa of mammals other than man was studied histologically or embryologically up to the 1920's (Schumacher, 1927). However, since then, it has been investigated histologically by only a few workers (Suenaga, 1960 ; Gaunt, 1965). Scanning electron microscopic findings for the rat buccal mucosa were recently reported, and epithelial papillae termed "buccal papillae" were found on its surface by Yoshioka and Muto (1976). Since there may also be buccal papillae on the buccal mucosa of other mammals, the mouse buccal mucosa was observed under the scanning electron microscope. This paper describes some of the findings obtained regarding epithelial papillae on the mouse buccal mucosa.

\section{Materials and Methods}

Three adult ddN mice (weighing $21.5 \mathrm{~g}-$ $51.5 \mathrm{~g}$, both male and female) were used for light microscopic observation. They were sacrificed under chloroform anesthesia. The buccal mucosa obtained from the mice was fixed in $10 \%$ formalin. After decalcification in 5\% nitric acid, the spec- 
imens were passed through a graded ethanol series and embedded in paraffin wax. They were serially cut into sagittal sections at 6 to $8 \mu$, and stained with hematoxylin-eosin.

In addition, 6 adult ddN mice (weighing $26.8 \mathrm{~g}-32.0 \mathrm{~g}$, both male and female) were used for scanning electron microscopic observation. They were sacrificed under chloroform anesthesia, and their buccal mucosa was fixed in $2.5 \%$ glutaraldehyde solution in $0.1 \mathrm{M}$ phosphate buffer ( $\mathrm{pH} 7.3$ ). The specimens were passed through a graded ethanol series and iso-amylacetate, and critical point dried in liquid $\mathrm{CO}_{2}$. They were coated with carbon and gold, and examined under a JEOL JSM-U3 scanning electron microscope at an accelerating voltage of $8 \mathrm{KV}$.

\section{Results}

\section{Light microscopic observations}

In the anterior part of the buccal mucosa, the surface is flat and smooth, and the corneum is less well developed. In the middle and posterior parts, the buccal mucosa has many fine furrows, a greater thickness of epithelium and a well developed corneum. Generally, connective tissue papillae are less well developed in the buccal mucosa, and in particular not observed in the anterior part. In the closed state of the mouth, rising of the mucosal surface, greater thickness of the epithelium and swarms of higher connective tissue papillae are recognized in the border region (Shumacher, 1924), extending in the posterior direction to the same level as the oral angle (Figs. 1,2). However, in the opening mouth, it is difficult to recognize the border region morphologically (Figs. 3, 4). Epithelial papillae of the buccal mucosa are scarcely observed in the anterior part, but are numerous in the middle and posterior parts. Also, in the transitional part be- tween the bucca and tongue, the epithelial papillae reveal low filiform papillae with a pointed apex. Each papilla consists of keratinized epithelium and a connective tissue papilla but with no secondary papillae.

2. Scanning electron microscopic observations

In the anterior part of the buccal mucosa along the lip margin, no epithelial papillae are observed. In the opening mouth, the folds in the region are not so remarkable as in the other parts of the buccal mucosa. This region is sharply distinguished from the other parts, by its lack of epithelial papillae and a sulcus in a vertical direction in the opening state. On the mucosa near the oral angle, a few hairs are observed.

Considerable epithelial papillae are observed on the buccal mucosa other than in the anterior region, as stated above. These papillae are variable in form and size, and their distribution and number show slight variations individually. In some cases, in the transitional part between the bucca and tongue, the lingual filiform papillae become gradually low in height and sparse in distribution towards the buccal mucosa, and in other cases, such transformations occur suddenly.

The form of these papillae can be distinguished into a filiform papilla type or wart type, beak type, flat oval type, and transitional types between these (Figs. 5-8). In some cases, the posterior-inferior part adjacent to the tongue body has relatively many epithelial papillae. The filiform papillae on the tongue body become gradually lower in height and wider in the interpapillary space and are succeeded by buccal epithelial papillae, which reveal an archlike arrangement (Fig. 9). In these cases, the buccal epithelial papillae, near the tongue body, often resemble the filiform papillae in form. In contrast, in the other cases, the buccal epithelial papillae near the tongue body are wart like in form, 
and are of sparse distribution. In the latter case, the epithelial papillae rapidly become lower in height and show a wart like form in the transitional part between the tongue and buccal mucosa.

In the middle part of the buccal mucosa, the epithelial papillae scattered on the surface show a beak like form with a dull or sharp tip. The papillae, near the soft palate, have a flat surface and are differentiated by a surrounding groove from the remaining mucous surface. The flat oval papillae occasionally resemble the palatal gemmal papillae but no taste pores are visible in the center of them (Fig. 10).

\section{Discussion}

\section{Border region}

According to embryological studies (Luschka, 1863 ; Ramm, 1905; Schumacher, 1924), the human buccal mucosa consists of two different parts : one is formed by the maxillar and mandibular mucosal parts directly adjoining the mucosal part of the upper and lower lips, and the other is the part between these upper and lower jaw parts including the extension of the oral angle. The latter was termed the marginal or border region (Saumregion der Wange) by Schumacher (1924), and shows the structure of the transitional part of the lips. In the early embryonic stage, the cheeks are formed by fusion of the maxillary and mandibular processes. At this time, the lip shows a definite division into an outer smooth zone, the pars glabra, and an inner zone with fine villi, the pars villosa, separated by the labial sulcus. The pars glabra then only unites while the pars villosa remains on the buccal mucosa as a border region. The border region is thus on the same level as the oral rima.

In the human fetus, the border region forms rough-surfaced villous prominences on its surface, so that it can be clearly distinguished from the smooth-surfaced parts above and below it. In human children and adults, even after loss of the villi, it is believed that the border region is readily distinguishable from the other parts by the greater thickness of the epithelium and the larger size of the connective tissue papillae (Watt, 1911; Yamazaki et al., 1948). Further, mixed salivary glands as seen in the mucosal part do not occur in this part. Suenaga (1960) has stated that in the dog buccal mucosa the border region shows a greater thickness of epithelium and a larger size and number of connective tissue papillae.

In the mouse buccal mucosa, in the closing mouth, rising of the mucosal surface, greater thickness of the epithelium and a larger size of the connective tissue papillae were observed as in the border region in man and the dog. However, in the opening mouth, they were not so remarkable. Based on these observations, it is considered that in the mouse buccal mucosa, rising of its surface reveals a flaccid condition of the buccal mucosa and it is questionable histologically whether there is a distinction with the border region. Also, the surface structure as revealed by scanning electron microscopy did not indicate that the border region was distinguishable from other parts of the buccal mucosa.

\section{Buccal papillae}

In the mouse buccal mucosa, Gaunt (1965) stated that the weakly cornified epithelium was extremely thick and abundant elastic fibers were seen beneath the epithelium. Although epithelial papillae were distinctly apparent in one of the published light microscopic photographs, he did not describe these epithelial papillae. Epithelial papillae on the rat buccal mucosa were described initially on the basis of scanning electron microscopy and named buccal papillae by Yoshioka and Muto (1976). In the most anterior part along the lip margin, hairs were found in small numbers. This 
finding only indicated that this region corresponded to the border region.

Numerous buccal papillae were found in the middle and posterior parts of the mouse buccal mucosa except the anterior part. These papillae displayed various forms as follows :

1, Filiform papilla form and wart form

2. Beak form

3. Flat oval form

Some buccal papillae showed transitional forms between these forms. Each buccal papilla contains a connective tissue papilla, but no secondary papillae.

Based on these observations, it is considered that the distribution of buccal papillae is not related to the border region, and that they do not have similarity to the epithelial papillae in the human newborn border region.

\section{Literatures cited}

1) Gaunt, W.Aa: Some observations upon the histology of the oral mucosa of the mouse. Acta Anat., 60: 516-530, 1965.

2) Luschka, H.: Die Leichenveränderung der Mundlippen bei neugeborenen Kinden. Z. Ration. Med., 3 Reiche, Bd. 18. 1863. Cited from Schumacher (1927).

3) Ramm, M.: Über die Zotten der Mundlippen und die Wangenschleimhaut beim Neugeborenen. Anat. H., 29 : 55-96. 1905.

4) Schumacher, S.: Der Bau der Wangen (insbesondere deren Innenbekleidung), verglichen mit dem der Lippen. $Z$. Anat. Entw., 73: 247-276. 1924.

5) Schumacher, S.: Die Mundhöle, Möllendorff's Handbuch der mikroskopischen Anatomie des Menschen. Bd. V, Tl. 1, 21-22. J. Springer, Berlin. 1927.

6) Suenaga, T.: On the sensory nerve supply of the lip and cheek in dog. Arch. Hist. Jap., 19 : 258-278. 1960.

7) Watt, J.C.: The buccal mucous membrane. Anat. Rec., 5: 447-455. 1911.

8) Yamazaki, J., Sakai, S. and Fujii, T.: On sensory innervation of the cheek mucous membrane in human adult (in Japanese). Tohoku Igaku Zasshi, 38: 1518. 1948.

9) Yoshioka, I. and Muto, H.: Surface structure of the tongue, palate and buccal mucosa of the rat. Okajimas Folia Anat. Jap., 52 : 297-312. 1976. 


\section{PLATES}




\section{Explanation of Figures}

\section{Plate I}

Fig. 1. Sagittal section of mouse buccal mucosa in the closed state of the mouth. $\times 130$

Fig. 2. High magnification of Fig. 1, showing high connective tissue papillae. $\times 320$

Fig. 3. Sagittal section in the mouth opening state. A few connective tissue papillae are seen, but the border region is not so remarkable. $\times 220$

Fig. 4. Buccal papillae (arrowed) in the middle part of the buccal mucosa, in the opening mouth. $\times 780$ 

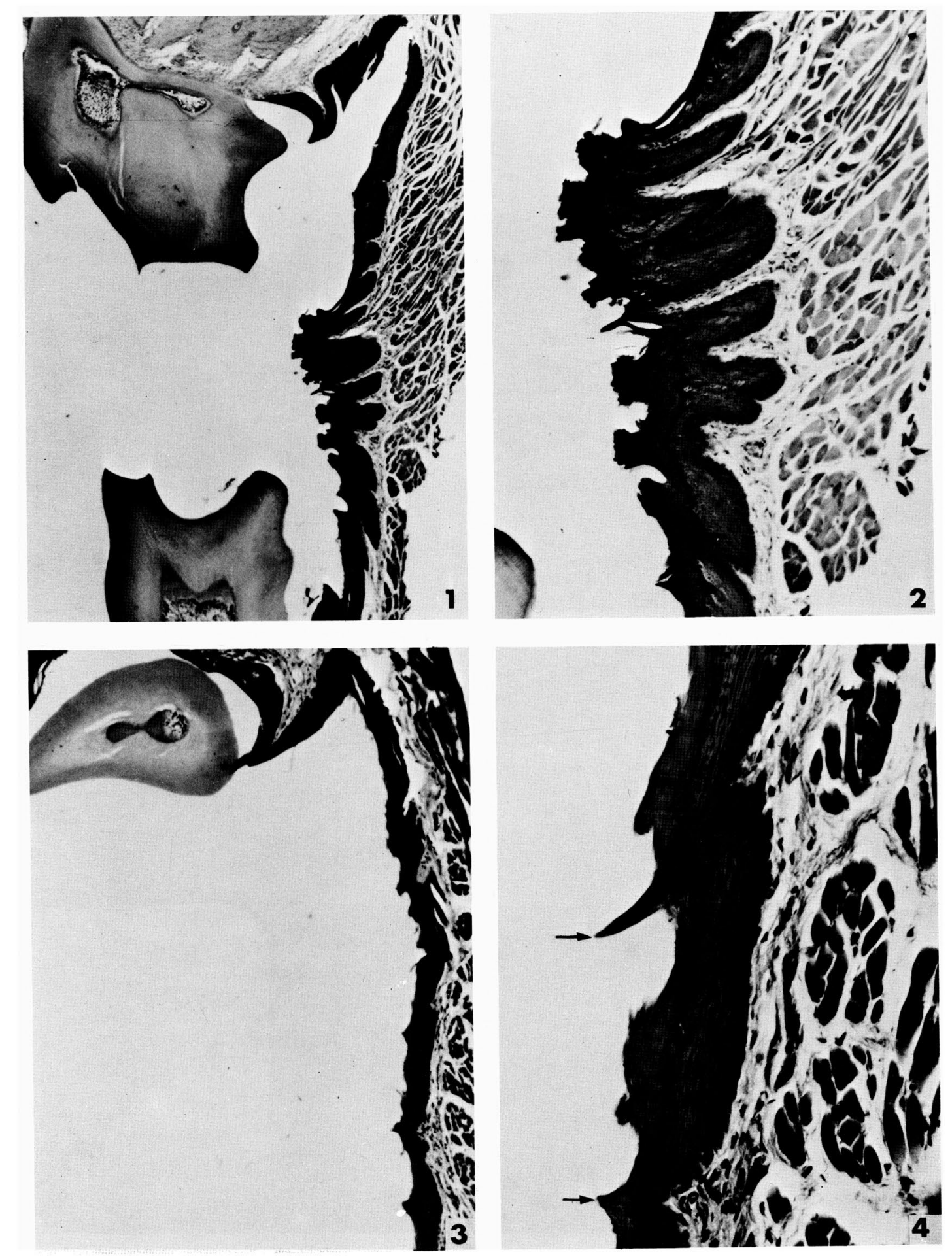


\section{Plate II}

Fig. 5. Scanning electron micrograph of the buccal mucosa in the posterior part near the tongue. $\times 140$

Fig. 6. Flat oval form buccal papillae in the middle part of the buccal mucosa. $\times 130$

Fig. 7. A beak form buccal papilla with a sharp tip. $\times 1000$

Fig. 8. A beak form buccal papilla with a dull tip. $\times 1000$ 

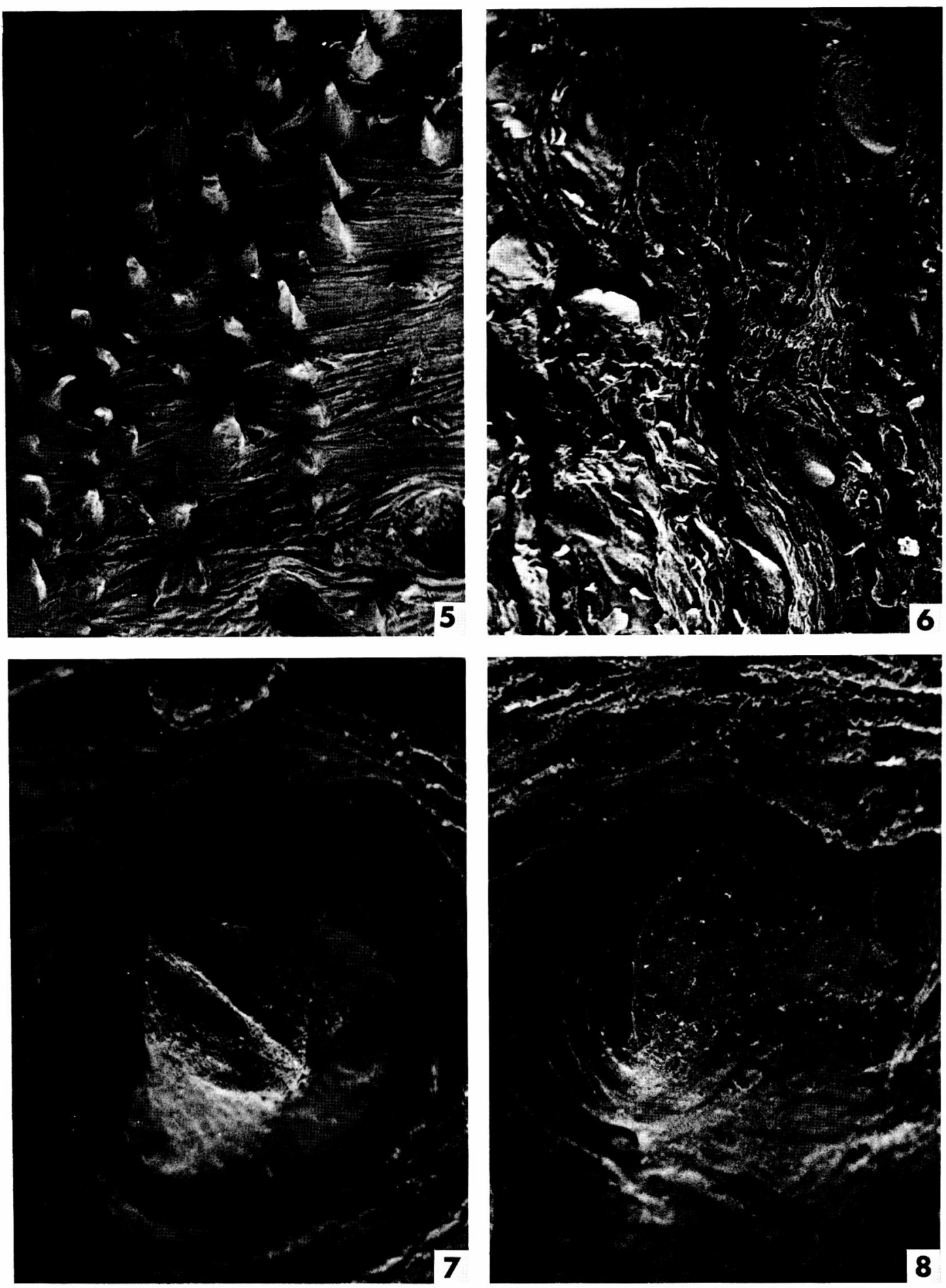


\section{Plate III}

Fig. 9. Arch-like arrangement of buccal papillae in the transitional part between the tongue and buccal mucosa. $\times 120$

Fig. 10. Buccal papillae near the soft palate. The papillae resemble the palatal gemmal papillae in form, but no taste pores are visible. $\times 320$ 

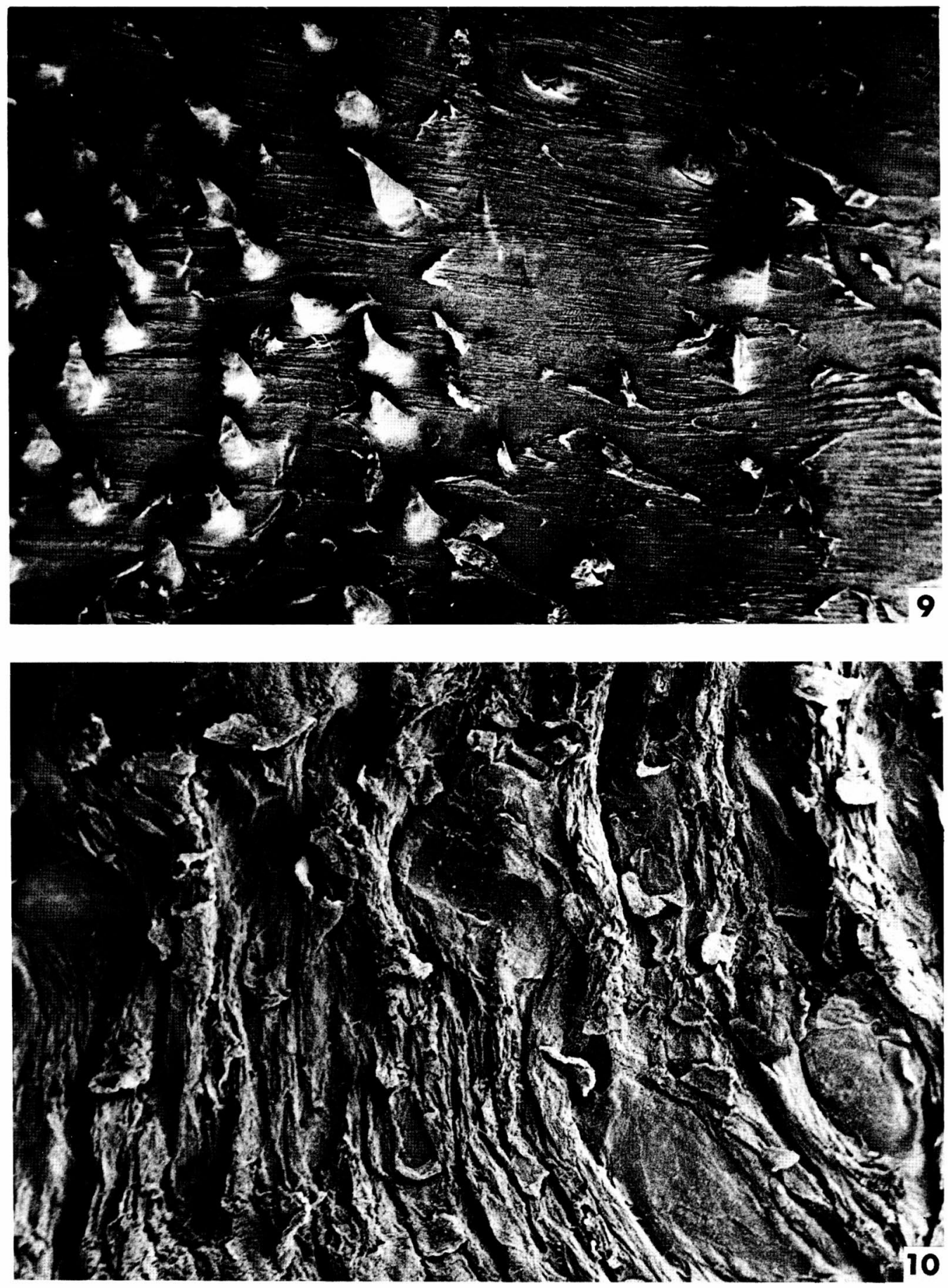